\title{
Large vessel vasculitis: is it more common than usually assumed?
}

\author{
M.A. Cimmino ${ }^{1}$, D. Camellino ${ }^{2}$ \\ ${ }^{1}$ Research Laboratory and Academic Division of Clinical Rheumatology; \\ ${ }^{2}$ Autoimmunology Laboratory, Department of Internal Medicine, University of Genova, Genova, Italy
}

\section{INTRODUCION}

L arge vessel vasculitis (LVV) is defined by the 2012 revised Chapel Hill Consensus Conference on the nomenclature of vasculitides as a vasculitis that affects large arteries more often than do other vasculitides, outside of organs such as muscle and kidney (1). It usually affects large arteries, such as the aorta and its branches, but may reach arteries of any size.

Takayasu arteritis (TAK) and giant cell arteritis (GCA), its major variants, share some common features, which on occasion make their separation difficult. LVV,

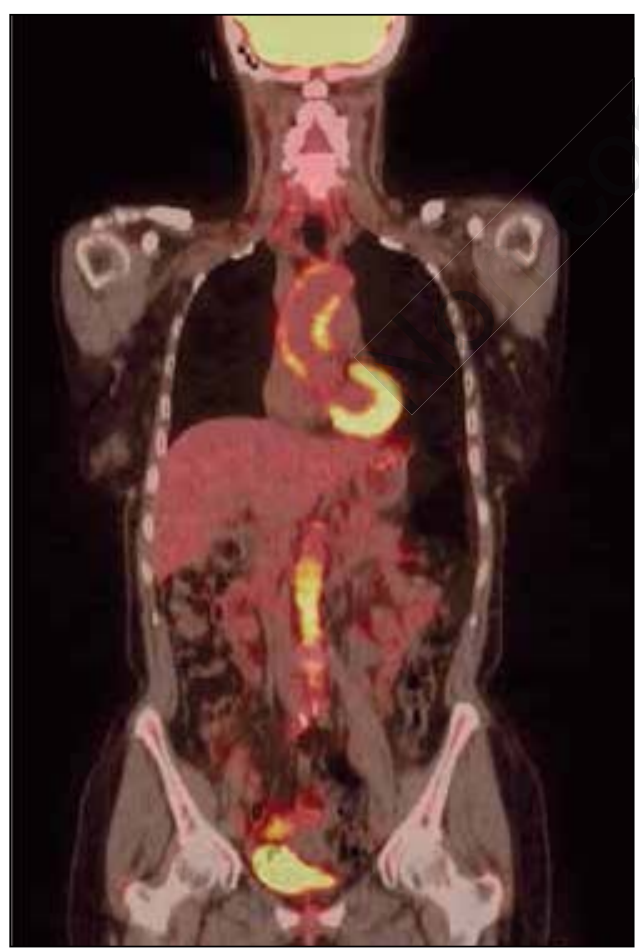

Figure 1 - FDG-PET fused with CT, coronal reconstruction. Aortitis of the thoracic and abdominal tract in a patient with giant cell arteritis. as previously defined, should not be considered a synonym of aortitis, which may occur as single location and fall into the single-organ vasculitides group (1), although strictly speaking the aorta itself is not an organ.

LVV, traditionally considered a rare condition, is currently recognized more often for two main reasons. On the one hand, new vascular imaging techniques, including MRI angiography, TC angiography, ultrasound (US), and PET-CT (Figure 1) have made its diagnosis more accessible (2); on the other hand, new therapies, the anti IL- 6 receptor monoclonal antibody tocilizumab (3) and the CTLA-4 Ig abatacept (4), have shown promising results in GCA and are calling more attention to this condition.

\section{THE LVV FAMILY}

The LVV family may include entities other than GCA and TAK (Table I). PET-CT has shown aortitis in about $30 \%$ of patients with polymyalgia rheumatica (PMR) (5). Isolated ascending aortitis (IAA), another variant, is unrelated in most patients to clinically recognizable GCA, TAK or PMR (6). It is often diagnosed only at surgery and may represent an aneurysmal form of unrecognized, or spontaneously healed, TAK or GCA. IAA occurs in younger patients compared to $\operatorname{GCA}(7,8)$ and often leads to aortic damage requiring surgery (8).

The definition chronic periaortitis (CP) indicates a condition in which an inflammatory mass surrounds the aorta and spreads to the peritoneum and, on occasion, the mediastinum $(9,10)$. Inflammation is present in the aortic wall, which is probably the starting site of the process. CP includes idiopathic retroperitoneal fibrosis and in-
Corresponding author Marco A. Cimmino Clinica Reumatologica, DIMI Viale Benedetto XV, 6 16132 Genova, Italia E-mail: cimmino@unige.it 
Table I - The family of large vessel vasculitides.

\begin{tabular}{|l|}
\hline - Giant cell arteritis \\
\hline $\begin{array}{l}\text { - Polymyalgia rheumatica-associated large vessel } \\
\text { vasculitis }\end{array}$ \\
\hline - Takayasu arteritis \\
\hline - Isolated ascending aortitis \\
\hline - Chronic periaortitis \\
Idiopathic retroperitoneal fibrosis \\
Inflammatory abdominal aortic aneurysms (AAAs) \\
\hline - IgG4-related disease \\
\hline
\end{tabular}

flammatory abdominal aneurysms. Finally, systemic IgG4-related disease (IgG4-RD), characterized by vasculitis in $22.5 \%$ of patients, is often associated with vessel damage by the surrounding inflammatory mass, but also by a primary form of aortitis (11). It could be the cause of most cases of $\mathrm{CP}$.

\section{DIFFERENTIAL DIAGNOSIS OF LVV}

GCA and TAK should be differentiated from a large group of inflammatory and non-inflammatory forms of aortic damage (Table II), which can be, or mimic, a LVV. Conditions falling in the first group are those associated with autoimmune diseases, such as rheumatoid arthritis, systemic lupus erythematosus, Behçet's disease, ankylosing spondylitis, sarcoidosis, relapsing polychondritis, Crohn's disease and Cogan's syndrome (12). Most rheumatologists believe, however, that aortitis is seldom seen in the above-mentioned conditions. In reality, in series of patients stud- ied histologically, aortitis associated with autoimmune diseases is at least as frequent as GCA and TAK (13). The reason why clinicians underestimate involvement of the aorta in autoimmune diseases is probably that clinical and laboratory signs of inflammation are easily attributed to the underlying primary condition and that vascular imaging techniques are not routinely used in this group of patients.

The remaining forms of aortic damage, some of which may be in part inflammatory, are those that occur without the frame of autoimmunity, such as atherosclerosis, infections (tuberculosis, syphilis, mycosis), and cancer (lymphoma, Erdheim-Chester disease). Furthermore, aortic lesions with features similar to aortitis are due to genetic conditions (Turner's syndrome, Ehlers Danlos disease, Marfan's syndrome), fibromuscular dysplasia, radiation-induced, and, possibly, drug-induced damage.

\section{HOW IS LVV DIAGNOSED}

Patients with LVV diagnosed as the result of a specific clinical query and subsequent vascular imaging are probably a minority. Most of them are identified during evaluation for non-specific systemic symptoms, such as fever, weight loss, and fatigue, mostly as part of the diagnostic panel to rule out cancer. Sometimes imaging performed for unrelated conditions may suggest the possibility of LVV. Between $2 \%$ and $8 \%$ of patients operated for asymptomatic aneurysms show histological

Table II - Diseases to consider in the differential diagnosis of primary LVV.

\begin{tabular}{|l|l|l|}
\hline \multirow{2}{*}{ Non-inflammatory } & Inflammatory \\
\cline { 2 - 3 } & Primarily not immune-mediated & Immune-mediated \\
\hline Marfan's syndrome & \multirow{2}{|l|}{$\begin{array}{l}\text { Infections } \\
\bullet \text { tuberculosis } \\
\bullet \text { Q fever } \\
\text { - syphilis } \\
\bullet \text { fungi }\end{array}$} & Sarcoidosis \\
\cline { 2 - 3 } Turner's syndrome & Behçet's disease \\
\cline { 2 - 3 } Ehlers-Danlos disease & Rheumatoid arthritis \\
\cline { 2 - 3 } & Atherosclerosis & Ankylosing spondylitis \\
\cline { 2 - 3 } & $\begin{array}{l}\text { Cancer } \\
\text { Fibromuscular dysplasia }\end{array}$ & SLE \\
\cline { 2 - 3 } & $\bullet$ lymphoma & Relapsing polychondritis \\
\hline
\end{tabular}

SLE, systemic lupus erythematosus. 
Table III - Epidemiology of large vessel vasculitides (LVV).

\begin{tabular}{|l|c|c|c|c|}
\hline Disease & Incidence & Prevalence & Geographical variations & Time trends \\
\hline GCA & $10-30 / 100,000$ & $7-280 / 100,000$ & $\boldsymbol{V}$ & $\boldsymbol{?}$ \\
\hline PMR-LVV & $?$ & $250 / 100,000$ & $?$ & $?$ \\
\hline TAK & $0.2 / 100,000$ & $0.4-4 / 100,000$ & $\boldsymbol{?}$ & $?$ \\
\hline IRF & $0.1-1.3 / 100,000$ & $1.4 / 100,000$ & $?$ & $?$ \\
\hline IgG4-RD & $0.3-1 / 100,000$ & $?$ & $?$ & $?$ \\
\hline
\end{tabular}

GCA, giant cell arteritis; PMR, polymyalgia rheumatica; TAK, Takayasu arteritis; IRF, idiopathic retroperitoneal fibrosis; IgG4-RD, IgG4related disease.

evidence of LVV $(6,14)$. The vagaries of this diagnostic approach indicate the possibility that many cases could remain undiagnosed.

\section{THE EPIDEMIOLOGY OF LVV}

The epidemiology of LVV is known only for GCA and TAK (15). These diseases have large geographical differences, with higher frequency of GCA in people of North European ancestry and lower in the Mediterranean basin and South America. On the contrary, TAK is more frequent in Asia and Japan, and less frequent in Sweden (16).

Table III shows a theoretical estimate of the prevalence of LVV. It is based on the data suggesting that about $2 / 3$ of patients with temporal arteritis and $1 / 3$ of those with PMR demonstrate aortitis at imaging (5, 17). If we add the other forms, the frequency of which can be only roughly estimated, the total prevalence of LVV could be in the range of that of RA, which is about 50 cases per 10,000 in the general population. This is the worst-case scenario, but the prevalence could be lower in areas where PMR and GCA are less diffused.

\section{CONCLUSIONS}

We believe that LVV is more frequent than usually implied in the literature; its diagnostic rate is likely to increase in the future due to higher awareness and wider use of vascular imaging techniques. An earlier diagnosis and treatment of LVV could diminish the incidence of irreversible damage of the vessel wall and the need for aneurysm surgery.
Conflicts of interests: the authors declare they are participating in the GIACTA clinical trial, sponsored by Roche.

\section{REFERENCES}

1. Jennette JC, Falk RJ, Bacon PA, et al. 2012 Revised International Chapel Hill Consensus Conference Nomenclature of Vasculitides. Arthritis Rheum. 2013; 65: 1-11.

2. Prieto-González S, Espígol-Frigolé G, GarcíaMartínez A, et al. The expanding role of imaging in systemic vasculitis. Rheum Dis Clin North Am. 2016; 42: 733-51.

3. Stone JH, Tuckwell K, Dimonaco S, et al. Efficacy and safety of tocilizumab in patients with giant cell arteritis: primary and secondary outcomes from a phase 3, randomized, double-blind, placebo-controlled trial. Arthritis Rheumatol. 2016; 68 (Suppl. 10).

4. Langford CA, Cuthbertson D, Ytterberg SR, et al. A randomized, double-blind trial of abatacept (CTLA-4Ig) for the treatment of giant cell arteritis. Arthritis Rheumatol. 2017; 69: 837-45.

5. Blockmans D, De Ceuninck L, Vanderschueren S, et al. Repetitive 18F-fluorodeoxyglucose positron emission tomography in isolated polymyalgia rheumatica: a prospective study in 35 patients. Rheumatology (Oxford). 2007; 46: 672-7.

6. Liang KP, Chowdhary VR, Michet CJ, et al. Noninfectious ascending aortitis: a case series of 64 patients. J Rheumatol. 2009; 36: 2290-7.

7. Talarico R, Boiardi L, Pipitone N, et al. Isolated aortitis versus giant cell arteritis: are they really two sides of the same coin? Clin Exp Rheumatol. 2014; 32: S55-8.

8. Espitia O, Samson M, Le Gallou T, et al. Comparison of idiopathic (isolated) aortitis and giant cell arteritis-related aortitis. A French retrospective multicenter study of 117 patients. Autoimmun Rev. 2016; 15: 571-6.

9. Rossi GM, Emmi G, Corradi D, et al. Idiopathic mediastinal fibrosis: a systemic immune-mediated disorder. a case series and a 
review of the literature. Clin Rev Allergy Immunol. 2017; 52: 446-59.

10. Vaglio A, Maritati F. Idiopathic retroperitoneal fibrosis. J Am Soc Nephrol. 2016; 27: 1880-9.

11. Perugino CA, Wallace ZS, Meyersohn N, et al. Large vessel involvement by IgG4-related disease. Medicine (Baltimore). 2016; 95: e3344.

12. Stone JR, Bruneval P, Angelini A, et al. Consensus statement on surgical pathology of the aorta from the Society for Cardiovascular Pathology and the Association for European Cardiovascular Pathology: I. Inflammatory diseases. Cardiovasc Pathol. 2015; 24: 267-78.

13. Ryan C, Barbour A, Burke L, Sheppard MN. Non-infectious aortitis of the ascending aorta: a histological and clinical correlation of 71 cases including overlap with medial degeneration and atheroma--a challenge for the pathologist. J Clin Pathol. 2015; 68: 898-904.
14. Kerr LD, Chang YJ, Spiera H, Fallon JT. Occult active giant cell aortitis necessitating surgical repair. J Thorac Cardiovasc Surg. 2000; 120: 813-5.

15. Richards BL, March L, Gabriel SE. Epidemiology of large-vessel vasculidities. Best Pract Res Clin Rheumatol. 2010; 24: 871-83.

16. Gudbrandsson B, Molberg $\varnothing$, Garen T, Palm $\varnothing$. Prevalence, incidence, and disease characteristics of Takayasu arteritis by ethnic background: data from a large, populationbased cohort resident in Southern Norway. Arthritis Care Res (Hoboken). 2017; 69: 278-85.

17. Blockmans D, Ceuninck L de, Vanderschueren $\mathrm{S}$, et al. Repetitive 18F-fluorodeoxyglucose positron emission tomography in giant cell arteritis: a prospective study of 35 patients. Arthritis Rheum. 2006; 55: 131-7. 